PREPARED FOR THE U.S. DEPARTMENT OF ENERGY, UNDER CONTRACT DE-AC02-76CH03073

PPPL-3972

PPPL-3972

UC-70

Simulation of DIII-D Flat q Discharges

by

C.E. Kessel, A. Garofalo, and T. Terpstra

June 2004

$\left.\stackrel{M}{M}\right|_{\substack{\text { PRInCETON PLASIMA } \\ \text { PHYSICS LABORATORY }}} ^{D}$

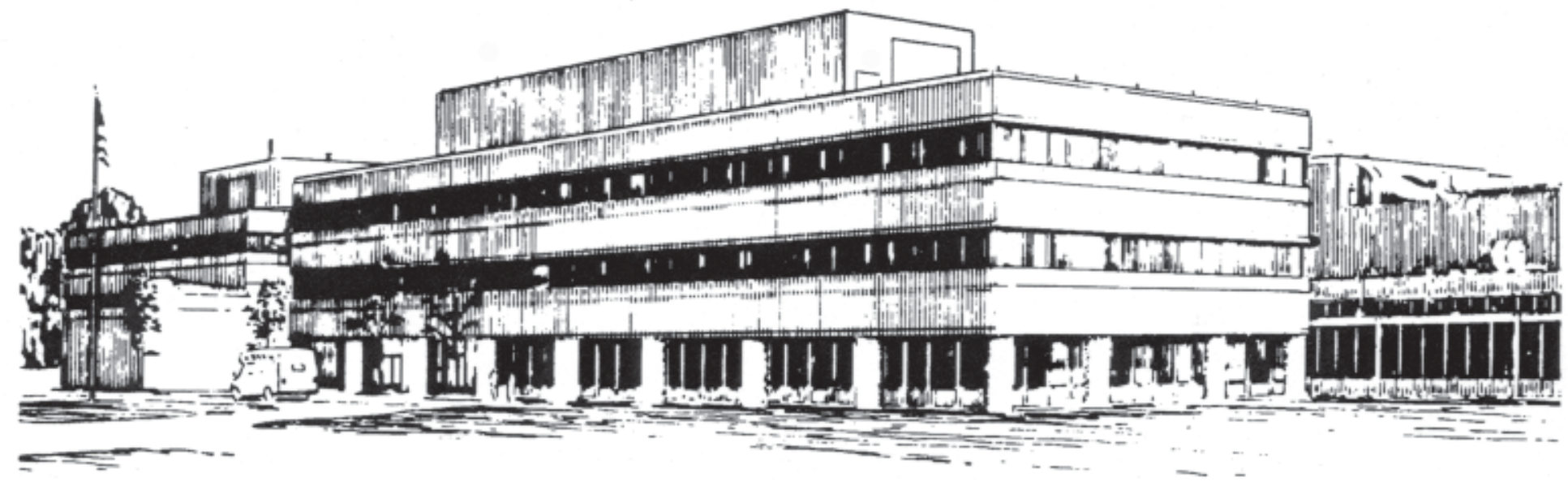

PRINCETON PLASMA PHYSICS LABORATORY PRINCETON UNIVERSITY, PRINCETON, NEW JERSEY 


\section{PPPL Reports Disclaimer}

This report was prepared as an account of work sponsored by an agency of the United States Government. Neither the United States Government nor any agency thereof, nor any of their employees, makes any warranty, express or implied, or assumes any legal liability or responsibility for the accuracy, completeness, or usefulness of any information, apparatus, product, or process disclosed, or represents that its use would not infringe privately owned rights. Reference herein to any specific commercial product, process, or service by trade name, trademark, manufacturer, or otherwise, does not necessarily constitute or imply its endorsement, recommendation, or favoring by the United States Government or any agency thereof. The views and opinions of authors expressed herein do not necessarily state or reflect those of the United States Government or any agency thereof.

\section{Availability}

This report is posted on the U.S. Department of Energy's Princeton Plasma Physics Laboratory Publications and Reports web site in Fiscal Year 2004. The home page for PPPL Reports and Publications is: http://www.pppl.gov/pub_report/

DOE and DOE Contractors can obtain copies of this report from:

U.S. Department of Energy

Office of Scientific and Technical Information

DOE Technical Information Services (DTIS)

P.O. Box 62

Oak Ridge, TN 37831

Telephone: (865) 576-8401

Fax: (865) 576-5728

Email: reports@adonis.osti.gov

This report is available to the general public from:

National Technical Information Service

U.S. Department of Commerce

5285 Port Royal Road

Springfield, VA 22161

Telephone: $1-800-553-6847$ or

(703) $605-6000$

Fax: (703) 321-8547

Internet: http://www.ntis.gov/ordering.htm 


\title{
Simulation of DIII-D Flat q Discharges
}

\author{
C. E. Kessel ${ }^{1}$, A. Garofalo ${ }^{2}$, and T. Terpstra ${ }^{3}$ \\ ${ }^{1}$ Princeton Plasma Physics Laboratory, P.O. Box 451, Princeton, NJ, USA 08543 \\ ${ }^{2}$ Columbia University, New York, NY, USA 10027 \\ ${ }^{3}$ General Atomics, 3550 General Atomics Ct., San Diego, CA, USA 92121
}

The Advanced Tokamak plasma configuration has significant potential for the economical production of fusion power. Research on various tokamak experiments are pursuing these plasmas to establish high $\beta$, high bootstrap current fraction, $100 \%$ non-inductive current, and good energy confinement, in a quasi-stationary state. One candidate is the flat q discharge produced in DIII-D[1], where the safety factor varies from 2.0 on axis, to slightly below 2.0 at the minimum, and then rises to about 3.5 at the $95 \%$ surface. This plasma is prototypical of those studied for power plants in the ARIES[2] tokamak studies. The plasma is produced by ramping up the plasma current and ramping down the toroidal field throughout the discharge. The plasma current reaches 1.65 MA, and the toroidal field goes from 2.25 to $1.6 \mathrm{~T}$. The $\mathrm{q}_{\text {min }}$ remains high and at large radius, $\rho \approx 0.6$. The plasma establishes an ITB in the ion channel, and transitions to H-mode. The free-boundary Tokamak Simulation Code[3] (TSC) is being used to model the discharge and project the impact of changes in the plasma current, toroidal field, and injected power programming.

\section{Simulation of Discharge \#115400}

The discharge \#115400 ramped the plasma current and toroidal field throughout the discharge to obtain a flat safety factor profile. The flat q profile is projected to have high $\beta$ limits[1]. The discharge suffered from a loss of density control and neutral beam source trips. However, in spite of this the $\beta$ reached $6 \%$, with the peak ion and electron temperatures at 6 and $3.75 \mathrm{keV}$, respectively, near the end of the discharge when the electron density was as high as $9 \times 10^{19} / \mathrm{m}^{3}$. Shown in Fig. 1 are the time histories of the plasma current, toroidal field, stored energy, density, and safety factor values. In order to model the discharge, the electron (tangential and core Thomson) and ion (CER) temperature profile data, and density (tangential and core Thomson) profile data are fit to analytic functions, in order to make interpolation more robust. The functions are given by, 


$$
\begin{aligned}
& T_{e, i}(\phi)=T(0)\left[c_{1}\left(1-\hat{\phi}^{b_{1}}\right)^{a_{1}}+c_{2}\left(1-\hat{\phi}^{b_{2}}\right)^{a_{2}}+c_{3} \tanh (\hat{\phi}, \Delta \hat{\phi})\right] \\
& n(\phi)=n(0)\left[\left(1-\hat{\phi}^{b_{1}}\right)^{a_{1}}+c_{2}(1-\hat{\phi})^{b_{2}} \hat{\phi}^{a_{2}}\right]+n\left(\phi_{b}\right)
\end{aligned}
$$

Here the argument is the local toroidal flux $(\phi)$ normalized to the toroidal flux enclosed by the plasma boundary $\left(\phi_{\mathrm{b}}\right)$. The density profiles are not evolved in the simulations, but are prescribed as a function of time. The temperature profiles are evolved, but enforced in the simulation by using an approach where the thermal diffusivity profiles are made to reproduce the temperature profile shape. The steady state energy equations are used to relate the thermal diffusivity to the temperature profile locally,

$|\nabla \phi|^{2} \chi_{e, i}=-\frac{\int_{0}^{\phi} H_{e, i}\left(\phi^{\prime}\right) d V}{\frac{d V}{d \phi} n(\phi) \frac{d T_{e, i}(\phi)}{d \phi}}$,

where $\mathrm{H}_{\mathrm{e}, \mathrm{i}}(\phi)$ is the heating profile minus the radiation, $\mathrm{n}(\phi)$ is the density, $\mathrm{V}$ is local volume, and $\mathrm{T}_{\mathrm{e}, \mathrm{i}}(\phi)$ is the temperature. The equipartition and any convective terms are neglected. Based on this the thermal diffusivities can be expressed as $\chi_{e, i}(\phi, t)=\chi_{e, i}{ }^{0}(t) \times F_{e, i}(\phi, t)$, where $\chi_{e, i}{ }^{0}(t)$ determines the magnitude of the temperatures and $\mathrm{F}_{\mathrm{e}, \mathrm{i}}(\phi, \mathrm{t})$ determines the temperature profile shape. This shaping factor is given by a normalized expression,

$$
F_{e, i}(\phi, t)=\frac{8 \pi^{2} P_{e, i}(\phi, t) n(0, t) R}{P_{e, i}\left(\phi_{b}, t\right) n(\phi, t) \frac{d V}{d \phi} \frac{1}{T(0, t)} \frac{d T_{e, i}(\phi, t)}{d \phi}}
$$

Here $\mathrm{P}_{\mathrm{e}, \mathrm{I}}$ is the deposited power enclosed by the flux surface. The desired temperature profiles from fitting the experimental data are inserted in the above formula during the simulation, and scaling factors are used to adjust $\chi_{\mathrm{e}, \mathrm{i}}{ }^{0}(\mathrm{t})$ to recover the peak temperature values. The results are thermal diffusivity profiles that can reproduce the experimental evolution to varying degrees of accuracy, and can be used with global energy confinement scalings to project to new 
experiments, say with different Ip, $\mathrm{B}_{\mathrm{T}}, \mathrm{P}_{\mathrm{INJ}}$, or density. It should be noted that the heating source deposition profiles are critical to obtaining a correct temperature evolution, and these profiles were generated by ONETWO analysis and reproduced in TSC. The entire simulation is still predictive, that is the forward time evolution of the energy equations is being solved.

In addition to this, since TSC is free-boundary, the poloidal field coil data is used to provide the entire discharge equilibrium evolution. The model includes the vacuum vessel, limiters, divertor strucutures, E-coils, and F-coils, and is shown in Fig. 2. Radial and vertical position feedback control is applied to keep the parameters close to the discharge. Isoflux shape control can be included as well to examine the impact of changing the plasma shape evolutions in future experiments, but has not been applied here.
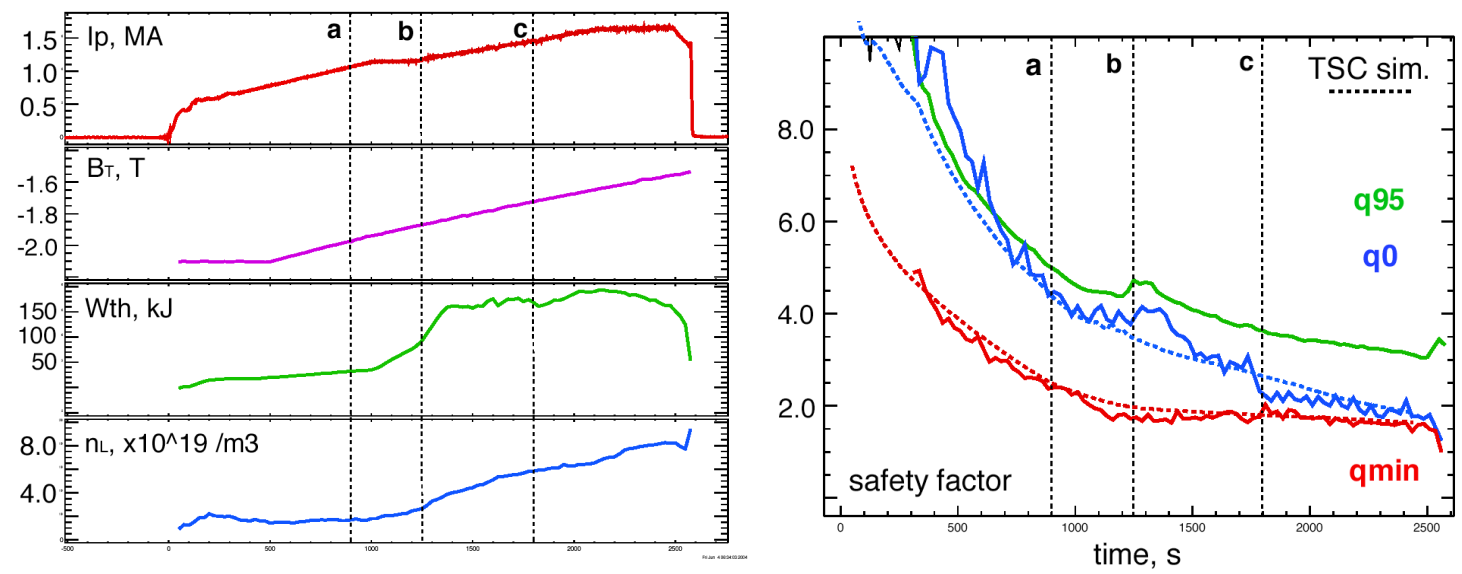

Figure 1. Time histories of the plasma current, toroidal field, stored energy and density for discharge \#115400. The letters denote the ion ITB onset (a), the L to H transition (b), and the NB power trip from 15.5 to $11 \mathrm{MW}(\mathrm{c})$. The TSC simulation safety factor values are also shown.

Also shown in Fig. 2 are the electron and ion peak temperatures from the experiment and from the simulation, showing reasonable agreement. The temperature profiles were also reproduced well. In Fig. 1 the safety factors at the axis and minimum from the TSC simulation are shown. From examination of several time histories; $\mathrm{R}, \mathrm{a}, \mathrm{Z}, \mathrm{li}, \kappa, \delta, \beta, \mathrm{W}_{\mathrm{th}}$, and $\mathrm{q}_{95}$, the discharge is being reproduced reasonably well. The plasma current is feedback controlled, while density and injected power are preprogrammed to match the experiment. 
The thermal diffusivities from this simulation will be used as a basis for the projection simulations. They will be scaled by the global energy confinement scaling IPB98(y,2)[4] using

$$
\chi_{e, i}(\phi, t)=\chi_{e, i}^{115400}(\phi, t) \frac{\tau_{E(y, 2)}^{115400}(t)}{\tau_{E(y, 2)}(t)}
$$

Improvements to the match between TSC simulations and experiments can be obtained by, 1) utilizing more time slices for experimental temperature profile data, only 8 were used here, 2) using more time point input in the TSC code, 24 time points were used here, 3) including dynamic terms in the derivation of $\chi$ as a function of $\mathrm{dT} / \mathrm{d} \phi$, and 4) installing more selfconsistent heating/CD source representations in TSC. Work continues to project the performance of this discharge.
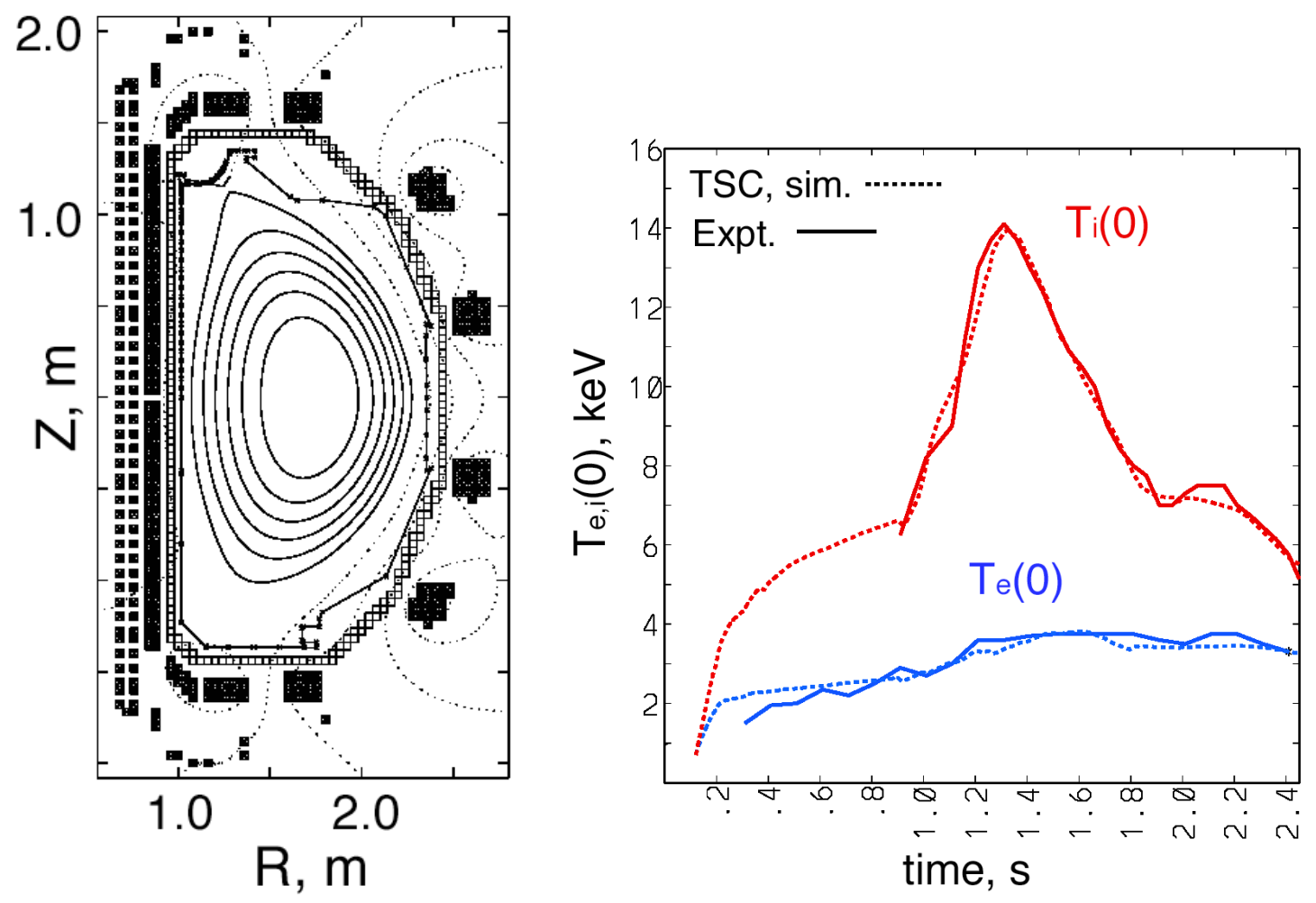

Figure 2. TSC simulation model showing the plasma at $910 \mathrm{~ms}$ in discharge \#115400, vacuum vessel, limiters, divertors, E-coils and F-coils. Also shown is a comparison of the experimental and simulation peak ion and electron temperatures. 
Work supported by DOE contract AC02-76CH0373

[1] R. J. Jayakumar, "Equilibrium and Stability Characteristics of DIII-D Discharges with Low Edge Safety Factor", Bull. Amer. Phys. Society, APS-DPP, Orlando, Florida, 2002.

[2] F. Najmabadi, $16^{\text {th }}$ IAEA Int'1. Conf. Fusion Energy, IAEA Vienna, Montreal, 1996; $18^{\text {th }}$ IAEA Int'l. Conf. Fusion Energy, IAEA Vienna, Sorrento, 1998.

[3] S.C. Jardin, N. Pomphrey, and J. DeLucia, J. Comp. Phys., vol. 66, pg. 481, 1986.

[4] ITER Physics Basis, Nuc. Fusion, vol. 39, pg 2175, 1999. 


\section{External Distribution}

Plasma Research Laboratory, Australian National University, Australia

Professor I.R. Jones, Flinders University, Australia

Professor João Canalle, Instituto de Fisica DEQ/IF - UERJ, Brazil

Mr. Gerson O. Ludwig, Instituto Nacional de Pesquisas, Brazil

Dr. P.H. Sakanaka, Instituto Fisica, Brazil

The Librarian, Culham Laboratory, England

Mrs. S.A. Hutchinson, JET Library, England

Professor M.N. Bussac, Ecole Polytechnique, France

Librarian, Max-Planck-Institut für Plasmaphysik, Germany

Jolan Moldvai, Reports Library, Hungarian Academy of Sciences, Central Research Institute for Physics, Hungary

Dr. P. Kaw, Institute for Plasma Research, India

Ms. P.J. Pathak, Librarian, Institute for Plasma Research, India

Ms. Clelia De Palo, Associazione EURATOM-ENEA, Italy

Dr. G. Grosso, Instituto di Fisica del Plasma, Italy

Librarian, Naka Fusion Research Establishment, JAERI, Japan

Library, Laboratory for Complex Energy Processes, Institute for Advanced Study, Kyoto University, Japan

Research Information Center, National Institute for Fusion Science, Japan

Dr. O. Mitarai, Kyushu Tokai University, Japan

Dr. Jiangang Li, Institute of Plasma Physics, Chinese Academy of Sciences, People's Republic of China

Professor Yuping Huo, School of Physical Science and Technology, People's Republic of China

Library, Academia Sinica, Institute of Plasma Physics, People's Republic of China

Librarian, Institute of Physics, Chinese Academy of Sciences, People's Republic of China

Dr. S. Mirnov, TRINITI, Troitsk, Russian Federation, Russia

Dr. V.S. Strelkov, Kurchatov Institute, Russian Federation, Russia

Professor Peter Lukac, Katedra Fyziky Plazmy MFF UK, Mlynska dolina F-2, Komenskeho Univerzita, SK-842 15 Bratislava, Slovakia

Dr. G.S. Lee, Korea Basic Science Institute, South Korea

Institute for Plasma Research, University of Maryland, USA

Librarian, Fusion Energy Division, Oak Ridge National Laboratory, USA

Librarian, Institute of Fusion Studies, University of Texas, USA

Librarian, Magnetic Fusion Program, Lawrence Livermore National Laboratory, USA

Library, General Atomics, USA

Plasma Physics Group, Fusion Energy Research Program, University of California at San Diego, USA

Plasma Physics Library, Columbia University, USA

Alkesh Punjabi, Center for Fusion Research and Training, Hampton University, USA

Dr. W.M. Stacey, Fusion Research Center, Georgia Institute of Technology, USA

Dr. John Willis, U.S. Department of Energy, Office of Fusion Energy Sciences, USA

Mr. Paul H. Wright, Indianapolis, Indiana, USA 
The Princeton Plasma Physics Laboratory is operated by Princeton University under contract with the U.S. Department of Energy.

\author{
Information Services \\ Princeton Plasma Physics Laboratory \\ P.O. Box 451 \\ Princeton, NJ 08543
}

Phone: 609-243-2750

Fax: 609-243-2751

e-mail: pppl_info@pppl.gov

Internet Address: http://www.pppl.gov 